\title{
Location of end-of-life care of children with cancer: a systematic review of parent experiences
}

\author{
Michelle Noyes $^{1}$, Anthony Herbert ${ }^{2}$, Susan Moloney ${ }^{1}$, Helen Irving ${ }^{3}$, and Natalie Bradford ${ }^{2}$ \\ ${ }^{1}$ Gold Coast University Hospital \\ ${ }^{2}$ Queensland University of Technology \\ ${ }^{3}$ Children's Health Queensland Hospital and Health Service
}

December 22, 2021

\begin{abstract}
Objective: To synthesise existing qualitative research exploring the experiences of parents caring for children with cancer during the end-of-life phase, and the factors that influence parental decision making when choosing the location of end-of-life care and death for their child. Results: This review included 15 studies involving 460 parents of 333 children and adolescents who died from progressive cancer. Where reported, the majority (58\%) of children died at home or in a hospital (39\%), with only a small fraction dying in a hospice. Factors impacting decision-making for location of care included the quality of communication and the quality of care available. Themes related to choosing home for end-of-life care and death included: honouring the child's wishes, familiarity of home, and parents' desire to be their child's primary carer. Preference for location of death in hospital included trust in hospital staff, practical logistics and the safety of the hospital environment.
\end{abstract}

\section{Hosted file}

Title page.docx available at https://authorea.com/users/452311/articles/550407-location-ofend-of-life-care-of-children-with-cancer-a-systematic-review-of-parent-experiences

\section{Hosted file}

Manuscript.docx available at https://authorea.com/users/452311/articles/550407-location-ofend-of-life-care-of-children-with-cancer-a-systematic-review-of-parent-experiences

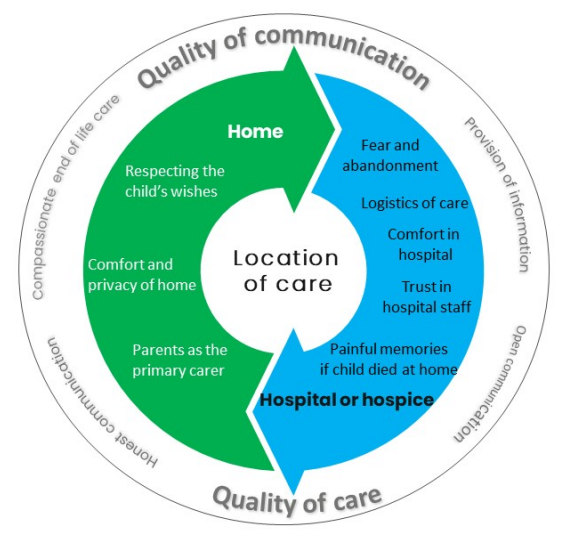




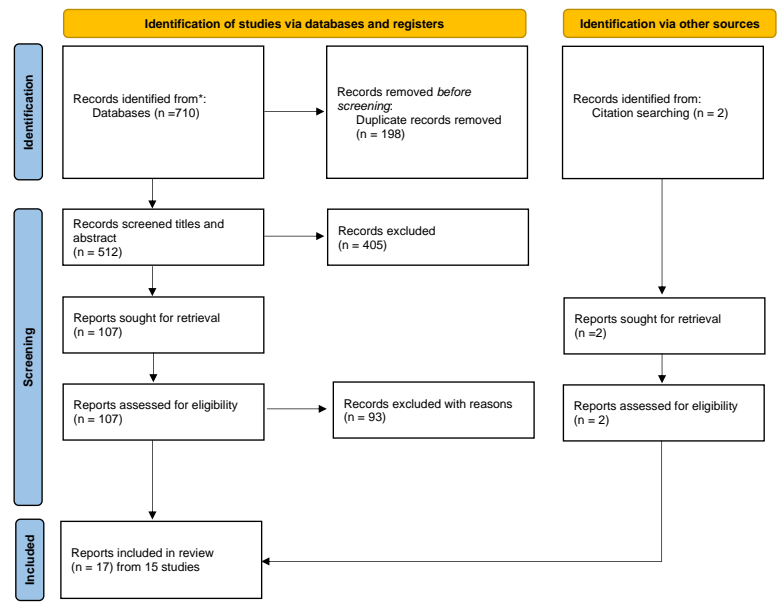

